\title{
RECENTES AVANÇOS E TENDÊNCIAS EM NOVOS MATERIAIS PARA ENERGIA RENOVÁVEL
}

\author{
A. F. DA SILVA JR ${ }^{*}$, M. F. DE CAMPOS ${ }^{* *}$ \\ CEFET/RJ - Campus Angra dos Reis ${ }^{*}$, Universidade Federal Fluminense ${ }^{* *}$ \\ Artigo submetido em 22/03/2016 e aceito em 05/12/2016 \\ DOI: $10.15628 /$ holos. 2016.4315
}

\section{RESUMO}

As novas tendências em energia renovável são qual é baseada em hidroelétricas. A tecnologia de comentadas. Parques eólicos vêm sendo significantemente ampliados ao redor do mundo. Painéis Solares já competem com outras formas de gerar energia. Células solares melhores e mais baratas vêm sendo desenvolvidas. Secas vem provocando a baterias vem sendo aperfeiçoada. Carros elétricos devem se tornar uma fração significativa da frota mundial dentro de 5 anos. Avanços recentes em pesquisas de materiais para baterias, painéis solares e necessidade de alterar a matriz energética brasileira, a motores elétricos são discutidos.

PALAVRAS-CHAVE: Energia solar, energia eólica, baterias, células solares, turbinas eólicas.

\section{RECENT ADVANCES AND TRENDS IN NEW MATERIALS FOR RENEWABLE ENERGY}

\begin{abstract}
The new trends in renewable energy are discussed. Wind farms have been significantly expanded around the world. Solar panels already compete with other forms of power generation. Better and cheaper solar cells have been developed. Drought has caused the need to change the Brazilian energy matrix, which is based on
\end{abstract}

hydropower. Battery technology has been improved. Electric cars must become a significant fraction of the world fleet within five years. Recent advances in research of materials for batteries, solar panels and electric motors are discussed.

KEYWORDS: Solar energy, wind energy, batteries, solar cel, wind turbines. 


\section{INTRODUÇÃO}

Antes de iniciar o texto específico sobre novos materiais, é pertinente mencionar o quadro energético no ano de 2015. Neste ano, no Sudeste do Brasil, foi registrada uma grande seca, a mais intensa dos últimos oitenta anos (http://www.bbc.com/news/world-latin-america30962813, recuperado em 01, janeiro, 2016). Também a Califórnia nos Estados Unidos vem sendo muito afetada por secas, por exemplo, com a cidade de San Diego neste momento construindo uma planta de dessalinização capaz de fornecer água para 300.000 pessoas (http://www.cbsnews.com/news/california-ocean-desalination-plant-drinking-water-in-sandiego/, recuperado em 01, janeiro, 2016). Evidentemente a seca afeta muito as hidrelétricas, que são responsáveis pela maior parte da matriz energética brasileira.

A água é muito preciosa para a agricultura, assim outras formas de produzir energia devem ser consideradas, preservando a água para consumo humano e outras aplicações. Nesse cenário, energias solar e eólica ganham especial relevância. Porém, energia solar apenas é gerada durante o dia, e a energia eólica depende da quantidade de vento. Assim, a mudança para energias renováveis solar e eólica impulsionam o desenvolvimento de baterias.

Outro setor tecnológico onde baterias são especialmente importantes são os veículos elétricos. Entre os veículos de nova geração estão carros híbridos, como o Toyota Prius, carro a célula de combustível, como o Toyota Mirai e carros elétricos como o Tesla Motors e Nissan Leaf. Existe, portanto, uma demanda por materiais para motores elétricos de alto desempenho. Estima-se que aproximadamente $50 \%$ da energia elétrica do mundo é consumida em motores elétricos (http://cleantechnica.com/2011/06/16/electric-motors-consume-45-of-globalelectricity-europe-responding-electric-motor-efficiency-infographic/, recuperado em 01, janeiro, 2016). Isto inclui a maioria das comodidades domésticas, como por exemplo ar condicionado, refrigeradores, freezers, máquinas de lavar roupa e pratos, liquidificadores, aspiradores de pó.

Novos materiais têm papel importante em todas essas aplicações, em painéis solares, em baterias para armazenamento de energia, em turbinas eólicas e em motores de alta eficiência. Ou seja, o avanço do setor de energia renovável depende do desenvolvimento de novos materiais, melhores e mais baratos.

Em algumas aplicações, por exemplo células solares e baterias, é fundamental não apenas o desempenho mas o custo. Estas são as principais tendências em desenvolvimento no momento. 


\section{SECA E POLUIÇÃO}

Existe uma relação entre poluição e seca. A poluição tende a diminuir a chuva (http://www.nature.com/news/2007/070305/full/news070305-11.html, recuperado em 01, janeiro, 2016). Isso talvez explique a seca de longa duração na Califórnia. O problema é agravado pela conexão global: por exemplo, a poluição chinesa pode atingir os Estados Unidos (http://www.cbsnews.com/news/pollution-from-china-alters-weather-in-us-west/, recuperado em 05, janeiro, 2016). Estima-se que seis dias (http://mashable.com/2014/01/23/us-chinapollution/, recuperado em 05, janeiro, 2016) é o tempo necessário para a poluição atravessar o oceano Pacífico e chegar na costa Oeste dos Estados Unidos. É possível que o problema de poluição e seca do hemisfério norte esteja afetando o hemisfério sul. Esse quadro indica que a seca no Brasil tende a se agravar, e o desmatamento na Amazônia sem dúvida também contribui para as secas que vêm sendo observadas nos últimos anos no Brasil.

\section{PLANTAS DE DESSALINIZAÇÃO NO BRASIL}

Uma das principais idéias em plantas de dessalinização é utilizar energia solar e eólica para essa finalidade. No caso de São Paulo, uma cidade a $800 \mathrm{~m}$ de altura, a solução com planta de dessalinização pode ser considerada praticamente descartada. Essa possibilidade se aplica a cidades ao nível do mar, como por exemplo San Diego ou Barcelona na Espanha (http://g1.globo.com/bom-dia-brasil/noticia/2014/09/usina-torna-potavel-agua-do-mar-e-dafim-problema-em-barcelona.html, recuperado em 05, janeiro, 2016). No Brasil, no Rio Grande do Norte, já estão sendo implantadas pequenas plantas de dessalinização, utilizando energia solar (https://www.ambienteenergia.com.br/index.php/2015/06/rn-energia-solar-ajuda-com-sistemade-dessalinizacao/26462, recuperado em 05, janeiro, 2016). Pelo menos nove estados do Brasil estão usando um sistema baseado em membranas que produz água dessalinizada a um custo 5 vezes maior do que água tratada (http://g1.globo.com/bom-dia-brasil/noticia/2014/09/sistemade-dessalinizacao-da-agua-ja-e-usado-em-nove-estados-no-brasil.html, recuperado em 05, janeiro, 2016). O objetivo para um futuro próximo é o desenvolvimento de sistemas que permitam dessalinização a um custo menor, talvez com apoio de energia solar e eólica.

\section{NOVAS PLANTAS SOLARES NO BRASIL}

A energia eólica já é mais barata do que a energia a carvão e estima-se que já em 2017 a energia solar também seja mais econômica que termoelétricas a carvão (http://www.huffingtonpost.in/2015/05/15/solar-conventional-azure-_n_7281772.html, recuperado em 05, janeiro, 2016). A queda de preço da energia solar vai provocar uma revolução energética no mundo. No Havaí (http://www.greentechmedia.com/articles/read/hawaiis-solar- 
grid-landscape-and-the-nessie-curve, recuperado em 05, janeiro, 2016) e Califórnia (http://www.greentechmedia.com/articles/read/retired-cpuc-commissioner-takes-aim-at-caisosduck-curve, recuperado em 05, janeiro, 2016) essa mudança já é perceptível. Na Alemanha, as energias eólica e solar reunidas já começam a superar a energia nuclear em dias de bastante vento e Sol (http://www.powermag.com/germany-solar-and-wind-power-each-surpass-nucleargeneration-since-mid-year/, recuperado em 05, janeiro, 2016).

O problema óbvio é que energia solar é gerada apenas durante o dia, ver Figura 1.

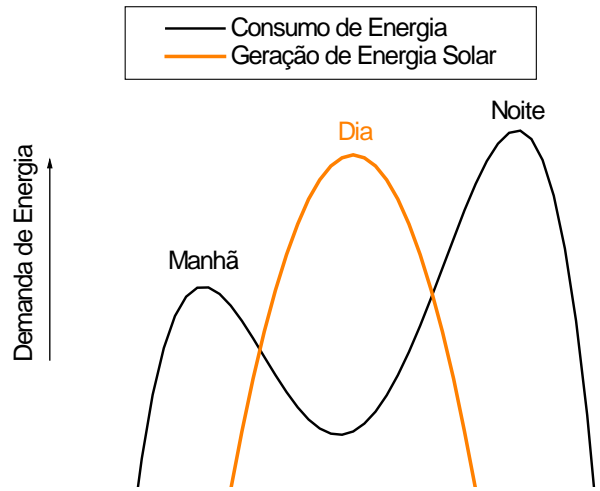

Figura 1. Horário de maior demanda de Energia pode não coincidir com o horário de maior geração de energia solar, que é tipicamente o meio-dia. Esquemático.

Assim, baterias são necessárias para armazenar a energia gerada pelo Sol. Esse problema gerou uma representação gráfica apelidada de curva do pato na Califórnia, ou curvas do Nessie (monstro do lago Ness), no Havaí, ver Figura 2. Baterias são aparentemente essenciais como forma de minimizar esse problema. Um outro detalhe importante é que em dias nublados ou chuvosos há menor produção de energia.

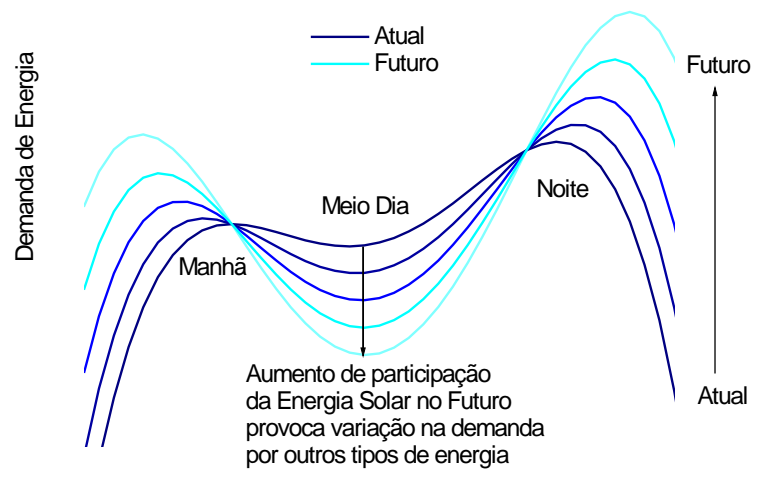

Figura 2. A maior participação de Energia Solar provoca variação na demanda por outras fontes de energia ao longo do dia. Esquemático. 
Para evitar problemas como o exposto na Figura 2, uma possibilidade é aumentar a geração de energia em hidrelétricas no final da tarde, controlando a vazão de água.

No Brasil, pretende-se combinar energia gerada por hidrelétricas com energia solar (http://economia.estadao.com.br/noticias/geral,reservatorios-de-hidreletricas-terao-paineispara-geracao-de-energia-solar-imp-,1658125, recuperado em 05, janeiro, 2016). Os painéis solares flutuantes diminuem a área do espelho d'água, evitando a evaporação da água dos reservatórios. Outra tendência é combinar parques eólicos com parques solares, aproveitando as linhas de transmissão já existentes (http://br.reuters.com/article/businessNews/idBRKBNOE81UM20140528, recuperado em 05, janeiro, 2016).

\section{MICROGRID}

A possibilidade de microgeração de energia torna-se possível até mesmo para a classe média. Embora a maioria dos projetos envolvam energia solar, existe a possibilidade de microgeração de energia eólica.

Um ítem muito importante é o tempo de retorno de investimento, ou "payback time", em inglês. No momento, o payback time no Brasil é de 3 a 6 anos. Se esse tempo for reduzido para um ou dois anos, muitas residências e indústrias investirão em painéis solares. Isso irá ampliar o microgrid. O problema mencionado de armazenamento de energia solar poderá favorecer operação industrial durante o dia.

O payback time é alto, pois o custo de painéis solares envolve também outros equipamentos, como inversores para conversão de corrente contínua em alternada (http://pureenergies.com/us/how-solar-works/solar-inverters/, recuperado em 5, janeiro, 2016), instalação dos painéis e manutenção.

Algumas situações podem dispensar inversores, como por exemplo a iluminação da rodovia arco metropolitano (http://global.kyocera.com/news/2015/0801_fmso.html, recuperado em 5, janeiro, 2016), ver Figura 3. 


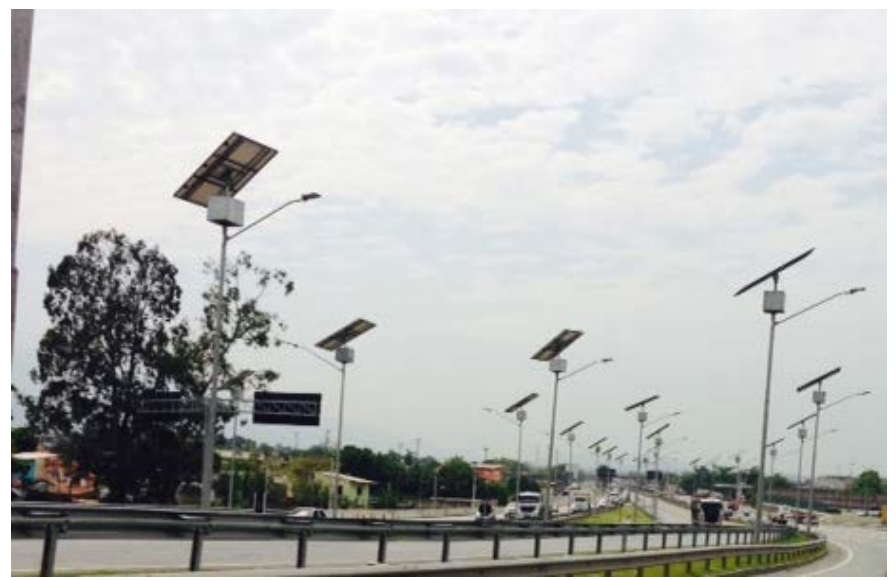

Figura 3. Sistema de iluminação noturno da Rodovia Arco Metropolitano, consistindo de painel solar, bateria chumbo ácido e lâmpada de LED. A energia é produzida durante o dia e é armazenada na bateria para prover iluminação durante a noite.

Soluções semelhantes à da rodovia arco metropolitano devem ser adotadas em muitos outros locais no mundo. Lâmpadas de LED estão se tornando a melhor opção para iluminação com economia de energia.

Podemos prever que em um futuro não muito distante alguns aparelhos deverão ter entrada para corrente contínua, de forma a aproveitar diretamente a energia produzida por painéis solares, ou então aproveitar a energia armazenada por baterias (http://www.teslamotors.com/powerwall, recuperado em 5, janeiro, 2016). O preço das baterias para armazenamento doméstico ainda é alto, mas deve cair em um futuro próximo.

\section{BATERIAS}

As baterias da rodovia arco metropolitano são do tipo chumbo-ácido (http://frank-sblog.blogspot.com.br/2015/01/projeto-de-iluminacao-do-arco.html, recuperado em 5, janeiro, 2016). A maioria dos automóveis a gasolina continua usando baterias chumbo-ácido, mas já existem companhias disponibilizando baterias de automóveis baseadas no composto LiFePO4 (http://www.starkpower.com/spnews/starterbatteries/, recuperado em 5, janeiro, 2016). A mudança de chumbo para lítio é uma tendência grande para ocorrer no mercado de baterias de carros comuns nos próximos anos (https://chargedevs.com/newswire/a123-shifts-focus-tostarter-batteries/, recuperado em 5, janeiro, 2016).

Em 2015, muitos "breakthroughs" (http://www.tomsguide.com/us/new-batterytechnology,news-20832.html, recuperado em 5, janeiro, 2016) foram reportados na área de baterias. A tecnologia dominante no momento são as baterias de Lítio íon. São essas baterias que 
permitem que recentes notebooks operem sem recarga por um período de 12 a 15 horas.

As baterias mais notáveis atualmente são as baterias que equipam os veículos da Tesla Motors, capazes de proporcionar autonomia de $426 \mathrm{~km}$ no Modelo $\mathrm{S}$ (http://www.greencarreports.com/news/1077122_2012-tesla-model-s-epa-range-of-265-miles89-mpge-efficiency, recuperado em 5, janeiro, 2016). O cátodo nessas baterias é do tipo NMC (níquel, manganês e óxido de cobalto).

As baterias do tipo LiFePO4, Wang e Sun (2015), são vantajosas em termos de custo, pois evitam elementos de liga caros como cobalto e níquel. Essa é uma das principais linhas de pesquisa atualmente. Além disso, novas técnicas de fabricação de baterias (http://qz.com/433131/the-story-of-the-invention-that-could-revolutionize-batteries-andmaybe-american-manufacturing-as-well/, recuperado em 5, janeiro, 2016) estão sendo estudadas. Baterias de Lítio Enxofre (LiS), Angulakshmi e Stephan (2015), também surgem como possíveis alternativas. Baterias $\mathrm{Li}$ ion em estado sólido também são cogitadas (http://www.greencarcongress.com/2015/08/201500827-seeo.html\#more, recuperado em 5, janeiro, 2016). Conforme mostra a Fig. 4, as baterias Li íon em estado sólido são as de maior potencial teórico.

Devido a intensas pesquisas e desenvolvimento tanto em indústrias como em universidades, espera-se para um futuro próximo grandes avanços na tecnologia de baterias, tanto em desempenho como em custo Nykvist e Nilsson (2015).

Outros tipos de baterias estão em desenvolvimento, por exemplo usando alumínio (http://phys.org/news/2015-04-ultra-fast-aluminum-battery-safe-alternative.html, recuperado em 5, janeiro, 2016), sódio (http://www.theengineer.co.uk/energy/news/sodium-ion-batteriesset-to-challenge-dominant-lithium-ion-technology/1020369.article, recuperado em 5, janeiro, 2016) ou zinco (http://www.forbes.com/sites/michaelkanellos/2015/05/19/is-zinc-ready-to-takeon-lithium-in-energy-storage/, recuperado em 5, janeiro, 2016). Por razões ambientais, é interessante evitar a utilização e chumbo. Mesmo que baterias de zinco ou sódio não consigam suplantar em termos de desempenho as baterias de Li íon, em termos de custo elas talvez possam ocupar a posição das baterias de chumbo, que permanecem até hoje com significativa porção do mercado.

No momento existem muitas possibilidades em pesquisa e desenvolvimento de baterias, sendo um setor onde patentes são aplicadas frequentemente. É uma área muito interessante para a atuação de pesquisadores brasileiros, especialmente os cientistas de materiais. Muitas das novas 
propostas para aperfeiçoamento de baterias envolvem nanotecnologia, Zhang et al. (2015), polímeros ou até mesmo papel. O momento atual permite uma oportunidade para o Brasil estabelecer uma indústria de baterias.

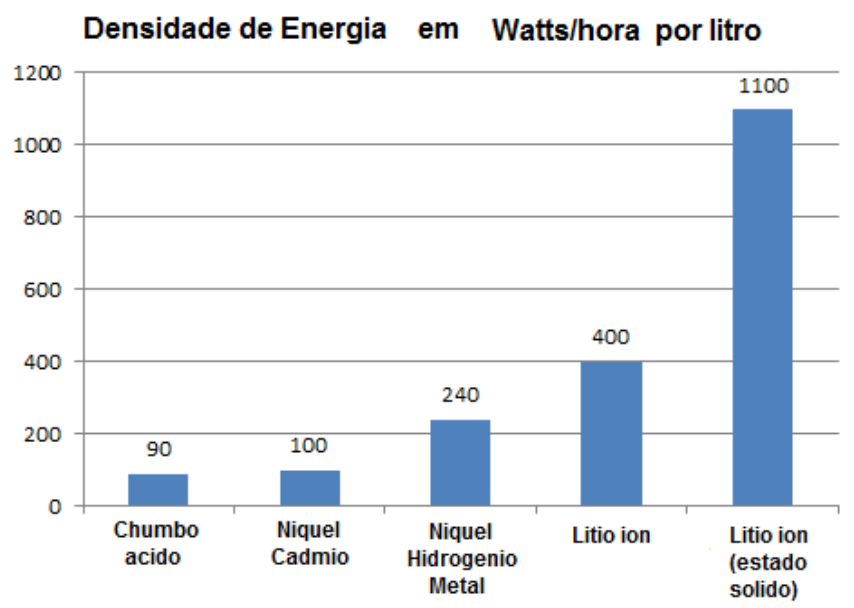

Figura 4. Comparação entre a máxima densidade de energia teórica para diferentes tipos de baterias (http://www.tomsguide.com/us/new-battery-technology,news-20832.html, recuperado em 1, janeiro, 2016).

\section{CÉLULAS SOLARES}

Células solares tem sido assunto de muitos estudos recentes, e também é esperada uma significante redução de custo para os próximos anos (http://cleantechnica.com/2015/01/29/solar-costs-will-fall-40-next-2-years-heres/, recuperado em 5, janeiro, 2016). Diferentes maneiras de aperfeiçoar células solares estão sendo consideradas. Métodos mais baratos de manufatura vêm sendo propostos, Goodrich, Powell, James, Woodhouse e Buonassisi (2013). Esforços nesse sentido também incluem filmes finos de CdTe (http://www.bbc.com/news/science-environment-27987827, recuperado em 5, janeiro, 2016).

Uma das possibilidades são células solares baseadas em perovskitas, Bullis (2015). Perosvkitas são compostos com formula ABX3, por exemplo, CaTiO3. As perovskitas apresentam muitas dificuldades técnicas para serem solucionadas antes de aplicação comercial (http://cleantechnica.com/2015/07/05/perovskite-solar-cells-what-this-breakthrough-needs-toget-to-market/, recuperado em 5, janeiro, 2016).

Considerando todo o esforço em pesquisa e desenvolvimento, e também um efeito de escala devido a ampliação do mercado para células solares, painéis solares deverão ocupar significante porção da matriz energética mundial já em um futuro próximo, dentro de menos de 10 anos 
(http://www.forbes.com/sites/federicoguerrini/2015/03/31/solar-power-to-become-cheapestsource-of-energy-in-many-regions-by-2025-german-experts-say/, recuperado em 5, janeiro, 2016).

Células solares são uma área importante e estratégica para o Brasil, país por onde passam o Equador e o Trópico de Capricórnio, e este tema deveria receber mais atenção no nosso país em esforços de pesquisa e desenvolvimento.

Um outro país com bastante exposição ao sol, a Austrália, já considera seriamente a energia solar (http://bze.org.au/media/newswire/australia-wind-power-already-cheaper-fossil-fuels-andsolar-right-behind-130211, recuperado em 5, janeiro, 2016). O território do Brasil inclui regiões como o semi-árido do nordeste onde o custo de geração deve ser muito baixo (www.aneel.gov.br/aplicacoes/atlas/pdf/03-Energia_Solar.pdf, recuperado em 5, janeiro, 2016). Energia elétrica barata pode impulsionar o desenvolvimento de indústrias em áreas pouco desenvolvidas como o sertão do nordeste.

\section{MATERIAIS PARA MOTORES ELÉTRICOS}

Além da geração de energia mais eficiente, deve ser considerado também o consumo mais eficiente. Motores elétricos consomem entre 40 e $50 \%$ da eletricidade gerada no mundo (http://cleantechnica.com/2011/06/16/electric-motors-consume-45-of-global-electricity-europeresponding-electric-motor-efficiency-infographic/, recuperado em 5, janeiro, 2016).

Uma maneira de tornar os motores elétricos mais eficientes é usando ímãs permanentes Widmer, Martin e Kimiabeigi (2015). Existem basicamente três tipos de motores de alta eficiência: (i) usando ímãs de terras raras (ii) usando ímãs de ferrite de estrôncio, (iii) sem ímãs permanentes.

Os motores dos carros elétricos produzidos pela Tesla Motors não usam ímãs permanentes. A Tesla Motors utiliza motores de corrente alternada trifásicos (http://www.teslamotors.com/blog/induction-versus-dc-brushless-motors, recuperado em 5, janeiro, 2016) com 4 polos. Esses motores utilizam alguns truques interessantes para melhorar eficiência, por exemplo usam rotor de cobre, sendo que esses rotores são resfriados com líquido.

O uso de rotores de cobre em substituição a rotores de alumínio fundidos é uma das tendências recentes para aumento de eficiência de motores elétricos (http://www.copper.org/environment/sustainable-energy/electricmotors/education/motor_text.html, recuperado em 5, janeiro, 2016). 
Diversos estudos recentes (http://www.iec.ch/etech/2015/etech_0315/tech-4.htm, recuperado em 5, janeiro, 2016) recomendam aumento de eficiência nos motores elétricos, como forma de economia de energia.

Motores utilizados em carros elétricos são um exemplo das tendências de projeto para melhorar eficiência. O BMW i3 usa um motor híbrido-síncrono (HSM) com ímãs permanentes (http://hybridfordonscentrum.se/wp-content/uploads/2014/05/20140404_BMW.pdf, recuperado em 5, janeiro, 2016). Os motores HSM são discutidos em mais detalhes por Tong (2014), e são uma opção típica em carros elétricos.

O Nissan Leaf usa ímãs permanentes em motor de corrente alternada (http://www.johnwmorehead.com/nissan-leaf-ev-and-what-is-a-permanent-magnet-ac-motor/, recuperado em 5, janeiro, 2016). O motor do Nissan Leaf também usa rotor do tipo gaiola de esquilo ou "squirrel cage", opção feita pela Tesla Motors, porém feita de alumínio. Deve ser ressaltado que o Nissan Leaf é um projeto de baixo custo, enquanto que os carros da Tesla Motors e o BMW i3 são bem mais caros. A primeira geração do Chevy Volt utilizava ímãs NdFeB em seus dois motores, mas um destes motores teve ímãs de NdFeB substituídos por ímãs de ferrite nas versões mais recentes (http://www.greencarreports.com/news/1096942_2016chevrolet-volt-powertrain-how-it-works-in-electric-hybrid-modes, recuperado em 5, janeiro, 2016). Detalhes do motor Chevy Volt mostram que trata-se de motores síncronos com ímãs permanentes (http://gm-volt.com/2015/01/16/2016-volt-transmission-observations/, recuperado em 5, janeiro, 2016).

A grande maioria dos motores de carros elétricos e híbridos comerciais emprega ímãs permanentes, com a notável exceção da Tesla Motors.

\section{CARROS ELÉTRICOS}

Em um espaço de tempo de 5 a 10 anos, os carros elétricos deverão ocupar significativa parcela do mercado, pelo menos em países desenvolvidos. O principal obstáculo ainda são as baterias. O problema é que as baterias rapidamente perdem a capacidade ao longo do tempo, e a única opção é a substituição (http://www.hybridcars.com/how-long-will-an-evs-battery-last/, recuperado em 1, janeiro, 2016). Por conta disso, carros elétricos usados tem baixo valor de revenda. Por outro lado, o Toyota Prius é um exemplo de carro híbrido extremamente bem sucedido. Um motorista de taxi na Áustria superou quilometragem de $1.000 .000 \mathrm{~km}$ sem trocar as baterias de seu Toyota Prius de segunda geração 
(http://www.carscoops.com/2015/07/austrian-taxi-driver-covers-1-million.html, recuperado em 1, janeiro, 2016). Isso não é exceção, muitos Toyota Prius continuam rodando após 10 anos de uso. Contudo, alguns precisaram ter substituição de baterias após muitos anos de uso (http://www.priusbatteryrepairofhouston.com/, recuperado em 1, janeiro, 2016). A idéia é que o carro elétrico seja bem mais simples e barato do que um carro híbrido. Porém um carro híbrido um pouco mais caro mas extremamente econômico pode ser vantajoso. A Toyota lançou recentemente o Toyota Mirai, movido a célula de combustível. Ainda não temos relatos de usuários sobre vantagens e desvantagens do Toyota Mirai, mas deve ser ressaltado que esse veículo tem tanques de hidrogênio com muito alta pressão (70 $\mathrm{MPa})$ (http://revistaautoesporte.globo.com/Noticias/noticia/2015/07/toyota-mirai-movido-

hidrogenio-bate-recorde-de-autonomia.html, recuperado em 1, janeiro, 2016), e a recarga de combustível causa alguma apreensão pois o hidrogênio pode causar acidentes (http://fortune.com/2015/05/13/an-energy-experts-love-hate-affair-with-toyotas-hydrogen-fuelcell-mirai/, recuperado em 1, janeiro, 2016). Resumindo, as baterias são o principal gargalo tecnológico no momento para que os carros elétricos substituam os carros a gasolina. As baterias apresentam notório problema de degradação com o tempo. Se as baterias se tornarem melhores e mais baratas, a tendência é o carro elétrico se tornar mais barato do que o carro a gasolina, devido à mecânica mais simples: em princípio basta ter motores elétricos conectados às rodas e a bateria carregada para impulsionar o carro.

\section{TURBINAS EÓLICAS}

Energia eólica já é mais barata que energia a carvão (http://cleantechnica.com/2015/04/13/solar-wind-power-prices-often-lower-fossil-fuel-powerprices/, recuperado em 5, janeiro, 2016), podendo ser mais barata até mesmo do que a energia gerada em hidrelétricas.

A tendência atual é o uso de turbinas eólicas cada vez maiores, tanto em terra como no mar (http://www.windpowermonthly.com/10-biggest-turbines, recuperado em 5, janeiro, 2016). Essas turbinas superam 100 metros de altura e, por exemplo, já existe turbina com 135 metros (http://cleantechnica.com/2015/08/09/is-this-the-future-of-wind-turbines/, recuperado em 5, janeiro, 2016).

A Siemens prefere $o$ uso de ímãs de terras raras nessas turbinas gigantes (http://phys.org/news/2015-08-offshore-turbine-boosts-energy-yield.html, recuperado em 5, 
janeiro, 2016) e está se preparando para adquirir enormes quantidades de ímãs nos próximos anos (http://www.bloomberg.com/article/2015-04-15/a9ANLTvgYzWg.html, recuperado em 5, janeiro, 2016). Cada turbina gigante exige várias toneladas de ímãs de terras raras.

No caso de turbinas gigantes, ímãs de ferrite não são tão interessantes pois ocupam 4-6 vezes o mesmo volume do que em sistema semelhante usando ímãs NdFeB. Ou seja, o uso de ímãs de ferrite aumenta muito o peso de cada turbina.

Turbinas eólicas vão requerer milhares de toneladas de ímãs de terras raras por ano (http://www.frontierrareearths.com/demand-for-neodymium-from-wind-turbines/, recuperado em 5, janeiro, 2016). Esta é uma interessante oportunidade para o Brasil, um dos países com maiores reservas de terras raras no mundo.

Recentemente vem sendo cogitadas turbinas eólicas supercondutoras (http://amlsuperconductivity.com/wordpress/wp-content/uploads/2015/07/Next-Generation-ofWind-Turbine-Generators-U.S.-Department-of-Energy.pdf, recuperado em 5, janeiro, 2016). Estas turbinas têm o potencial para serem mais leves e baratas. Entretanto, a dificuldade de manter partes do gerador super-resfriadas com Hélio líquido é um problema considerável (https://www.newscientist.com/article/mg21729005-600-wind-turbines-supercharged-withsuperconductors/, recuperado em 5, janeiro, 2016). Turbinas supercondutoras não são idéia muito recente, e tem sido objeto de estudos acadêmicos há vários anos Ohsaki, Terao e Sekino (2010); Jensen, Mijatovic e Abrahamsen (2013).

\section{CONCLUSÕES}

A matriz elétrica brasileira deve ser alterada em parte no futuro próximo, com um maior espaço sendo ocupado por energias eólicas e solar. Hidrelétricas são essenciais para complementar a energia gerada por sol e vento. A energia a carvão estará mais cara que energia solar dentro de três anos. Termoelétricas tendem a ser substituídas por instalações eólicas e solares. Essa tendência já é observada em países como Estados Unidos e Alemanha.

A geração de energias eólica e solar depende da quantidade de vento e sol, sendo necessário gerar energia de outra maneira quando sol ou vento não estão disponíveis, ou então armazenar energia. Portanto, a geração de energia solar deve impulsionar a indústria de baterias.

A energia solar favorece a instalação do microgrid, com cada consumidor podendo produzir sua própria energia. A rede elétrica precisa se adequar ao microgrid, que tende a se tornar cada vez mais relevante no decorrer dos anos. 
Carros elétricos são viáveis, mas ainda é necessário aperfeiçoar as baterias, em termos de custo e desempenho. O Brasil deveria investir em pesquisa, desenvolvimento e manufatura de baterias, lâmpadas de LED e células solares. Para aproveitar suas reservas de terras raras, o Brasil poderia produzir turbinas eólicas gigantes.

\section{AGRADECIMENTOS}

CNPq, FAPERJ.

\section{REFERÊNCIAS}

Angulakshmi, N. \& Stephan, A. M. (2015). Efficient electrolytes for lithium-sulfur batteries. Front. Energy Res. Disponível: http://dx.doi.org/10.3389/fenrg.2015.00017.

Bullis, K. (2015). A Cheap Material Boosts Solar Cells by 50 Percent. MIT Technology Review.

Goodrich, A. C., Powell, D. M., James, T. L., Woodhouse, M. \& Buonassisi, T. (2013). Assessing the drivers of regional trends in solar photovoltaic manufacturing. Energy Environ. Sci.,6, 2811-2821

Jensen, B. B., Mijatovic, N. \& Abrahamsen, A. B. (2013). Development of superconducting wind turbine generators. J. Renewable Sustainable Energy 5, 023137.

Nykvist, B. \& Nilsson, M. (2015). Nature Climate Change 5, 329-332.

Ohsaki, H., Terao, Y. \& Sekino, M. (2010). Wind turbine generators using superconducting coils and bulks. Journal of Physics: Conference Series, Volume 234, Part 3.

Tong, W. (2014). Mechanical Design of Electric Motors . April 28. CRC Press.

Wang, J. \& Sun, X. (2015). Olivine LiFePO4: the remaining challenges for future energy storage. Energy Environ. Sci., 2015,8, 1110-1138.

Widmer, J. D. , Martin, R. \& Kimiabeigi, M. (2015). Electric Vehicle Traction Motors Without Rare Earth Magnets. Sustainable Materials and Technologies 3, 7-13. 
Zhang, X., Zhang, Q., Zhang, Z., Chen, Y., Xie, Z., Wei, J. \& Zhou, Z. (2015). Rechargeable $\mathrm{Li}-\mathrm{CO} 2$ batteries with carbon nanotubes as air cathodes. Chem. Commun., 51, 1463614639. 